\title{
Assessing Vulnerability Trends and Magnitudes in Light of Human Responses to Floods in Karonga District, Malawi
}

\author{
I.N.K. Mwalwimba \\ Department of Geography and Earth Sciences, Millennium University, Malawi
}

\begin{abstract}
Globally, it is now accepted that vulnerability assessment should be considered as a starting point for the development of disaster risk reduction (DRR) programmes. Despite this global emphasis, this study argues that the task of disaster risk management in Malawi has been hitherto characterized by post-event humanitarian action and relief activities, with little consideration on the causes and vulnerability assessment per se. Consequently, Malawi lacks a strategy to invest its scarce resources to minimize the damage related to disasters. In this regard, the paper aims to assess the factors that generate the trends and magnitudes of vulnerability with respect to policy makers' response to flood disasters in Karonga district. The study used structured questionnaire, GPS-receiver and observation to collect data from household participants and villages location points. The sample size of household participants was 200, selected from 10 villages in Group Village Headman Matani Mwakasangila and Mujulu Gweleweta. The participants were selected through simple random sampling method. Data from household participants was analyzed using SPSS while coordinates from GPS receiver were analyzed using Quantum Geographic Information System(QGIS). The study revealed that physical (61\%), social (55\%), economic $(55 \%)$, environmental (60\%) of the factors were respectively placed in the category of "very important" for generating vulnerability while the cultural factors (37\%) were in the "important" category. In addition, the relationship between these vulnerability factors and flood severity revealed strong, medium and weak statistical correlation (r) values. On the other hand, only the cultural factors (pvalue $=0.009$ ) were significant. The study revealed the vulnerability trends and magnitudes of 9.6\%, 32.4\% and $58 \%$ in the category of "less vulnerable", "more vulnerable" and "most vulnerable" respectively. Finally, the paper recommends that policy makers should strengthen disaster risk reduction and management strategies in order to reduce human vulnerabilities and infrastructural damage.
\end{abstract}

Keywords: Disaster Risk Reduction, Disasters, Flood hazards, Vulnerability Assessment, Vulnerability

\section{Introduction}

The significant loss of life from flood hazards in Malawi is triggered by the vulnerability of communities living in the flooded areas. Vulnerability entails a better understanding of how natural hazards become disasters. While vulnerability underscores how natural hazards turn into disasters, its assessment is essential for disaster risk reduction (DRR) programmes' implementation. Globally, it is now accepted that vulnerability assessment should be considered as a starting point for the development of DRR programmes. Despite this global emphasis, this study argues that the task of disaster risk management in Malawi has been hitherto characterised by post-event humanitarian action and relief activities, with little consideration on the causes and vulnerability assessment per se. Consequently, Malawi lacks a strategy to invest its scarce resources to minimize the damage related to disasters. Studies indicate that appropriate DRR interventions can be implemented only when the vulnerability of people to a particular hazard has been assessed (Bath et al., 2016; Birkmann, 2006) - hence the necessity of this study.

When assessing flood vulnerability or resilience due caution has to be exercised since it is important to understand that resilience and vulnerability are not necessarily opposite ends of a spectrum for individuals or communities. For example, a community, may be vulnerable to a particular flooding but they may have resilience in terms of external support, or social safety nets from the Government or NGOs that offers material support. In this case their resilience is not a function of the potential for loss or vulnerability. (Buckle, et al, 2001).

In the case of floods in T/A Kilupula, the communities may not be necessarily vulnerable if the Government intervenes with appropriate strategies. This approach of looking at vulnerability is also supported in literature (Trosper 2002). The capacity of communities to absorb external shocks due to social, political or environmental changes is a function of three conditions i.e. "ability to self-organize, ability to buffer disturbance, and capacity for learning and adapting". For Malawi the "disturbance" could be buffered through Government or other external support intervention.

\section{Study Methodology}

\subsection{Study design}

The study adopted a cross-sectional survey utilizing quantitative research method. Household survey (structured questionnaire), Geographic Position System (GPS-receiver) and observation were used to collect data.

\subsection{Study location}

The study was carried in GVH Matani Mwakasangila and Mujulu Gweleweta in Traditional Authority Kilupula of Karonga district in northern part of Malawi. 


\section{International Journal of Science and Research (IJSR) \\ ISSN: 2319-7064}

ResearchGate Impact Factor (2018): 0.28 | SJIF (2019): 7.583

\subsection{Sampling}

Household participants were selected through simple random sampling. Participants were determined according to the number of the households of the village to the total households of Group Village Headman (GVH). From each village, households were randomly selected to give a representation of all affected households in that village. This most vulnerable households were targeted based on distance from rivers and elevation thresholds.

The sample size was calculated using a formula $n=$ $\frac{z^{2} p q}{d^{2}}$ developed by Fisher et al. (1983), where: $\mathrm{n}=$ Minimum sample size $=$ Constant, standard normal deviation $(1.96$ for 95\% confidence interval), $\mathrm{p}=$ Proportion of the target population (The targeted adoption rate is at least $20 \%$ ), $\mathrm{q}=$ Alternate proportion $(1-\mathrm{p})$, which is $1-0.2=0.8, \mathrm{~d}=$ Acceptable margin error, which is 0.05 at $95 \%$ confidence interval: $n=\frac{(1.96)^{2}(0.8)(1-0.8)}{0.05^{2}}=246$

The total sample size calculated at $20 \%$ targeted population was 246 household participants. However, during the survey 200 participants were interviewed face-to face. From the sample size of 200, the number of household participants in the villages was calculated based on the population of households of each village to the total population of the GVH and also the households' location relative to river position and elevation thresholds.

\subsection{Data Collection}

Household questionnaire survey was developed based on the Pressure and Release (PAR) Model. The PAR model is a tool for showing how disaster occurs when natural hazards such as floods affect vulnerable people. The questionnaire captured household information relating to flooding and vulnerability. GPS coordinates were recorded for each village headman after administering household questionnaire .They helped to gather information pertaining to household location points and depth (height above sea level). The coordinates were recorded in order to map location of households from which data was collected

\subsection{Data Analysis}

Data collected from households using structured-close ended questionnaire was entered and analyzed using SPSS version 20. Descriptive statistics such as percentage and tables were used in determining various vulnerability issues that were assessed i.e. physical, social, economic, environmental and cultural factors. The statistical analysis such as chi-square tests and probability value ( $\mathrm{p}$-value) were used to determine the associations between demographic characteristics and vulnerability factors as well as exposure, susceptibility, resilience and vulnerability factors. The analysis was at $95 \%$ confidence level i.e. p- value 0.05. Correlation was also used to establish relationship that depicted the trends between factors generating vulnerability and severity of past and recent floods. This helped to determine the factor that increases the trends and magnitudes of vulnerability in relation to the occurrence of floods.Coordinates collected using the GPS receiver were entered into Quantum Geographic Information System (QGIS) to produce a polygon. The polygon was over layered on top of the topographic map of T/A Kilupula. Then the map was produced to show the location of villages in which the households were sampled.

\subsection{Measurement variables}

Vulnerability trends and magnitudes was predicted under conditions of community exposure, susceptibility and resilience. Codes 0-1 were employed to predict the trends and magnitudes. A code of " 0 " meant either the household was exposed, susceptible or not resilient. On the other hand, a code of " 1 " meant either the household was not exposed, not susceptible or resilient to flood disasters. Total average of probability trends and magnitudes on exposure, susceptibility and resilience conditions in the category of less vulnerable, more vulnerable and most vulnerable were obtained to depict the vulnerability trends and magnitudes.

Furthermore, a set of variables from the five underlying vulnerability factors i.e. physical, social, economic, environmental and cultural factors were used. These variables considered all the three stages that lead to the generation of vulnerability in the PAR model.

To measure vulnerability based on PAR Model of the highlighted factors, two sets of categories were used. The first category was used when assessing characteristics generating vulnerability. This category used measurement scale of $1-3$, in which 1 meant less important, 2 important and 3 very important. The second category measured the level of the vulnerability of the elements at risk. Elements at risk are those assets that people's lives rely upon. They include (but not limited to) houses, water supply, crops, livestock, infrastructures, social services (schools, health posts, \& electricity), natural environment. The vulnerability of people increases if these elements do not withstand the impact of a hazard (Blaikie et al, 2005). This category used a measurement scale of $1=$ not vulnerable, $(0-25 \%), 3=$ slightly vulnerable $(26-50 \%), 5=$ vulnerable $(51-75 \%)$ and $7=$ severely vulnerable $(76-1000 \%)$. In Table 2, characteristics generating vulnerability (A) and elements at risks (B) have been combined with its measurements in all outcomes of underlying vulnerability factors

\begin{tabular}{|l|l|l|}
\hline \multicolumn{2}{|c|}{ Vulnerability Variables } \\
\hline Outcome & \multicolumn{1}{|c|}{ Measurement Rate } & \multicolumn{1}{c|}{ Measurement Rate (\%) } \\
\hline & Conditions Generating Vulnerability (A) & Elements at Risk (B) \\
& 1= Less important & 1= Not vulnerable (0-25) \\
& 2= Important & 3= Slightly vulnerable (26-50) \\
& 3= Very important & 5= Vulnerable (51-75) \\
& & 7= Severely vulnerable (76-100) \\
\hline Physical & - Poor construction standards & - Houses \\
\hline
\end{tabular}

Volume 9 Issue 4, April 2020 www.ijsr.net 


\section{International Journal of Science and Research (IJSR)}

ISSN: 2319-7064

ResearchGate Impact Factor (2018): 0.28 | SJIF (2019): 7.583

\begin{tabular}{|c|c|c|}
\hline & $\begin{array}{l}\text { - Safe shelter awareness } \\
\text { - Lack of building materials }\end{array}$ & $\begin{array}{l}\text { - Toilets } \\
\text { - Wells and boreholes } \\
\text { - Roads and bridges } \\
\end{array}$ \\
\hline Social & $\begin{array}{l}\text { - Lack of Knowledge in DRR } \\
\text { - Lack of Skills to cope with urgent needs } \\
\text { - Lack of local institutions support }\end{array}$ & $\begin{array}{l}\text { - Health posts } \\
\text { - Schools } \\
\text { - Warehouses }\end{array}$ \\
\hline Economic & $\begin{array}{l}\text { - No credit unions } \\
\text { - Lack of income generating activities } \\
\text { - Poverty } \\
\text { - Lack of alternative livelihoods }\end{array}$ & $\begin{array}{l}\text { - Staple crops (cassava \& maize) } \\
\text { - Cash crops (rice) } \\
\text { - Livestock (cattle) } \\
\text { - Trading \& fishing }\end{array}$ \\
\hline Environmental & $\begin{array}{l}\text { - Pressure on arable land } \\
\text { - Residing in prone areas } \\
\text { - Scarcity of water \& energy } \\
\end{array}$ & $\begin{array}{l}\text { - River channels } \\
\text { - Forest cover } \\
\text { - Land and soil quality } \\
\end{array}$ \\
\hline Cultural & $\begin{array}{l}\text { - Traditional beliefs } \\
\text { - Cultural conflicts } \\
\text { - Defiance to safety measures } \\
\text { - Absence of ownership }\end{array}$ & - Broken social networks \\
\hline
\end{tabular}

The explanatory variables included household demographic characteristics such as age, sex, marital status, education level and source of income of household heads. This approach is also supported by Buckle et al. (2000) who argues that the widely used vulnerability indicators are age, education, gender, income, employment, ethnicity, household composition and type of dwellings.

\section{Results}

The analysis revealed the results as outlined below.

\subsubsection{Characteristics Generating Vulnerability}

Table 3.1.1: Underlying Vulnerability Factors

\begin{tabular}{|c|c|c|c|c|}
\hline $\mathrm{n}=200$ & \multicolumn{3}{|c|}{ Measurement rates: 1=less important; 2= important; 3= Very important } \\
\hline $\begin{array}{c}\text { Outcome variables of underlying } \\
\text { vulnerability factors }\end{array}$ & $\begin{array}{c}\text { Average \% in category } \\
\text { of less important }\end{array}$ & $\begin{array}{c}\text { Average \% in category } \\
\text { of important }\end{array}$ & $\begin{array}{c}\text { Average \% in category } \\
\text { of very important }\end{array}$ & $\begin{array}{c}\text { Total average } \\
\text { vulnerability factor each }\end{array}$ \\
\hline Physical & 12 & 27 & 61 & 100 \\
\hline Social & 16 & 29 & 55 & 100 \\
\hline Economic & 17 & 28 & 55 & 100 \\
\hline Environmental & 19 & 21 & 60 & 100 \\
\hline Cultural/human & 30 & 37 & 33 & 100 \\
\hline
\end{tabular}

The results show that the physical factors (61\%), environmental factors $(60 \%)$ and the social and economic factors $(55 \%)$ are above the average $(50 \%)$ on the category of very important factors generating vulnerability while the cultural factors (33\%) are below the average and greater on the category of less important $(30 \%)$ than all the factors.

\subsubsection{Level of the Vulnerability of the Elements at Risk}

Table 3.1.2: Elements at Risk in Vulnerability Factors

\begin{tabular}{|c|c|c|c|c|c|}
\hline $\mathrm{n}=200$ & \multicolumn{5}{|l|}{ Scale Range: 1= Not vulnerable (0-25\%); 3= Slightly vulnerable (26-50\%); 5= Vulnerable (51-75\%); } \\
$7=$ Severely vulnerable (76-100\%)
\end{tabular}

The analysis of the results shows that the physical elements are severely vulnerable $(84 \%)$; the economic elements are vulnerable $(63 \%)$ while the environmental and social elements are slightly vulnerable (47\%) and (39\%) respectively (Table, 3.1.2).

Table 3.1.3: Relationship of Vulnerability Factors and Demographic characteristics

\begin{tabular}{|c|c|c|c|c|c|c|c|c|c|c|}
\hline Variables & \multicolumn{2}{|c|}{ Physical } & \multicolumn{2}{c|}{ Social } & \multicolumn{2}{c|}{ Economic } & \multicolumn{2}{|c|}{ environmental } & \multicolumn{2}{c|}{ cultural } \\
\hline & $p$-value & chi $^{2}$ & $p$-value & chi $^{2}$ & $p$-value & chi $^{2}$ & $p$-value & chi $^{2}$ & $p$-value & chi $^{2}$ \\
\hline Age & 0.322 & 14.453 & 0.095 & 20.335 & 0.085 & 33.285 & 0.147 & 38.011 & 0.0764 & 35.306 \\
\hline Sex & $\mathbf{0 . 0 0 6}$ & 8.547 & 0.164 & 5.745 & 0.164 & 18.507 & $\mathbf{0 . 0 2 6}$ & 5.223 & $\mathbf{0 . 0 0 4}$ & 10.997 \\
\hline Marital status & $\mathbf{0 . 0 1 0}$ & 26.305 & 0.179 & 21.977 & $\mathbf{0 . 0 0 3}$ & 6.106 & $\mathbf{0 . 0 2 6}$ & 14.203 & $\mathbf{0 . 0 4 3}$ & 28.543 \\
\hline Occupation & 0.121 & 28.063 & 0.397 & 47.868 & $\mathbf{0 . 0 3 8}$ & 30.436 & 0.288 & 56.842 & 0.121 & 40.756 \\
\hline Education & 0.281 & 37.529 & 0.084 & 24.609 & 0.203 & 47.814 & $\mathbf{0 . 0 0 3}$ & 22.664 & $\mathbf{0 . 0 3 0}$ & 27.230 \\
\hline
\end{tabular}

Volume 9 Issue 4, April 2020 www.ijsr.net 


\section{International Journal of Science and Research (IJSR) \\ ISSN: 2319-7064}

ResearchGate Impact Factor (2018): 0.28 | SJIF (2019): 7.583

The results of the associations between vulnerability factors and demographic characteristics show that there is no relationship between age and all other vulnerability factors (Table 3.1.3).

Table 3.1.4: Relationships between Vulnerability Factors and Flood Severity

\begin{tabular}{|c|c|c|c|c|c|}
\hline \multirow{2}{*}{$\begin{array}{c}\text { Flood } \\
\text { severity }\end{array}$} & \multicolumn{5}{|c|}{ Vulnerability factors } \\
\cline { 2 - 6 } & Physical & Social & Economic & Environmental & Cultural \\
\cline { 2 - 6 } & $(r)$ & $(r)$ & $(r)$ & $(r)$ & $(r)$ \\
\hline Recent floods & 0.509 & 0.734 & 0.477 & 0.578 & 0.897 \\
\hline Past floods & 0.162 & 0.271 & 0.262 & 0.123 & 0.009 \\
\hline
\end{tabular}

The relationship between the factors and flood severity revealed a strong, medium and weak correlation coefficient ( $r$ ) value for all the factors, that is, they determine the trends and magnitudes of vulnerability. However, the result showed that only the cultural factor was significant to the past floods (Table 3.1.4). It was observed that the correlation difference between past and recent floods in all the vulnerability factors were due to frequency occurrence of floods caused by siltation of rivers and cultivation in river banks.

Table 3.1.5: Trends and Magnitudes of Vulnerability level under some conditions

\begin{tabular}{|c|c|c|c|c|c|c|c|}
\hline \multicolumn{5}{|c|}{ Vulnerability factors } & $\mathrm{Z}=\beta_{\mathrm{i}} \mathrm{x}_{\mathrm{i}}$ & \multicolumn{3}{c|}{ Probability (Y=j) in \% } \\
\hline Exposure & Susceptibility & resilience & & Less V & More V & Most V \\
\hline Physical & 0 & 0 & 0 & -2.6333 & 4 & 21 & 75 \\
\hline Economic & 0 & 1 & 0 & 1.4031 & 5 & 38 & 57 \\
\hline Social & 0 & 1 & 1 & -1.2301 & 6 & 41 & 53 \\
\hline Environmental & 1 & 1 & 0 & 4.4324 & 26 & 16 & 58 \\
\hline Cultural & 1 & 1 & 1 & 1.7991 & 7 & 46 & 47 \\
\hline Average total Probability of Vulnerability Trends \& Magnitudes & 9.6 & 32.4 & 58 \\
\hline
\end{tabular}

The results on the trends and magnitudes of vulnerability shows a probability $9.6 \%, 32.4 \%$ and $58 \%$ on the categories of less vulnerable, more vulnerable and most vulnerable respectively.

\subsubsection{Location of Villages in T/A Kilupula in relation to elevation threshold}

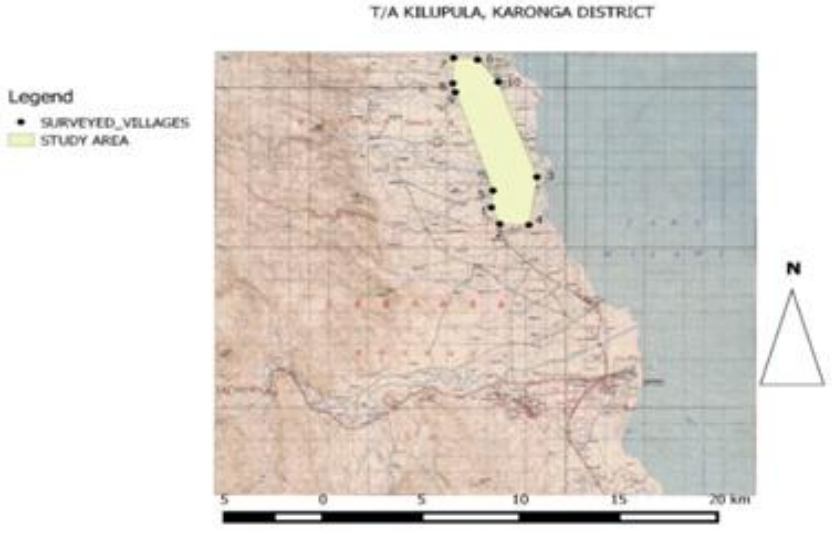

Figure 3.1: Spatial Distribution of Villages in GVH

Mwakasangila and Gweleweta of Traditional Authority Kilupula

The analysis of the village location points reveals that most households are situated in the low lying areas of Lake Malawi (Figure 3.1.5). All the places surveyed, shows the elevation threshold below 500ASL, except one in Village headman Mangulu (Table 3.1.6).

\subsection{6: Attribute location points of village headmen}

\begin{tabular}{|c|c|c|c|c|}
\hline ID & Name of Village & $\begin{array}{c}\text { X } \\
\text { Coordinate }\end{array}$ & $\begin{array}{c}\text { Y } \\
\text { Coordinate }\end{array}$ & $\begin{array}{c}\text { Elavation } \\
\text { (m ASL) }\end{array}$ \\
\hline 1 & $\begin{array}{c}\text { SHALISONI } \\
\text { MWAKASANGILA }\end{array}$ & 596243 & 8912519 & 490 \\
\hline 2 & FUNDI HAMIS & 596661 & 8911482 & 493 \\
\hline 3 & $\begin{array}{c}\text { MATANI } \\
\text { MWAKASANGILA }\end{array}$ & 598548 & 8914426 & 480 \\
\hline 4 & CHIPAMILA & 598146 & 8911433 & 486 \\
\hline 5 & $\begin{array}{c}\text { ELIYA } \\
\text { MWAKASANGILA }\end{array}$ & 596316 & 8913570 & 483 \\
\hline
\end{tabular}

\begin{tabular}{|c|c|c|c|c|}
\hline 6 & CHAKWERA & 595541 & 8921760 & 486 \\
\hline 7 & MANGULU & 594320 & 8921878 & 502 \\
\hline 8 & CHIMALABANTHU & 594279 & 8920284 & 496 \\
\hline 9 & PHANISO & 594403 & 8919728 & 489 \\
\hline 10 & GWELEWETA & 596584 & 8920365 & 485 \\
\hline
\end{tabular}

\subsection{Discussion}

The analysis of the results has revealed five underlying factors that generate the trends and magnitudes of people's vulnerability to respond to flood disasters. The analysis showed increasing trends and magnitudes of vulnerability under conditions of exposure, susceptibility and resilience in all the five vulnerability factors. The physical factors were revealed to the most vulnerable $(75 \%)$, followed by the environmental factors (58\%), economic factors (57\%), social factors $(53 \%)$ and cultural factors $(47 \%)$. The average total probability trends and magnitudes in the conditions of exposure, susceptibility and resilience were 9.6\%, 32.4\% and $58 \%$ in the category of "less vulnerable", "more vulnerable" and "most vulnerable" respectively (Table 3.1.5). Below is a separate discussion of all the five vulnerability factors and their policy implication:

\subsubsection{Factors Generating Vulnerability Trends and Magnitudes}

3.2.1.1 Physical Factors: The relationship between physical factors and flood severity showed that there is weak (but positive) correlation value, $(r=0.162)$ for the past floods and medium correlation $(r=0.509)$ for the recent floods (Table 3.1.4). This result suggests that the physical factors determine the trends and magnitudes of vulnerability. The cause of this could be attributed to lack of knowledge and skills related to shelter and safety. For example, the results of the quantitative analysis revealed the average of the physical conditions generating vulnerability to be $61 \%$ in the category of "very important" (Table 3.1.1). The physical conditions found were lack of permanent buildings (68\%), lack of safe shelter awareness $(66 \%)$ and poor construction standards of infrastructures $(49 \%)$.It was also noted that

Volume 9 Issue 4, April 2020 


\section{International Journal of Science and Research (IJSR) \\ ISSN: 2319-7064}

ResearchGate Impact Factor (2018): 0.28 | SJIF (2019): 7.583

most infrastructures such as houses are traditional and substandard, predominantly made up of grass thatch and mud floors, prone to leaking and thereby becoming more vulnerable to floods. For, example the physical elements that were found to be "severely vulnerable" with an average of 84\% (Table 3.1.2) included houses, toilets, wells and infrastructures -roads and bridges

The results of the association between demographic characteristics and physical factors (Table 3.1.3), suggests that the physical factors influence the vulnerability of an individual to respond to floods based on sex and marital status. This is because the results revealed a significant association between sex, marital status and physical factors (Table 3.1.3).It was noted women, widow and divorced live poor houses made up of mud floors and thatched grass which is prone to floods. Moreover, they receive little attention from the community leaders in times of humanitarian actions and relief activities because of their limited access to power in the communities. In this case, it was observed that stakeholders responsible for emergency response do not provide adequate support to these sections of population.

3.2.1.2 Social Factors: The results of the relationship between social factors and flood severity showed there is weak (but positive) correlation, $(r=0.27)$ for the past floods and strong correlation $(r=0.734)$ for the recent floods (Table 3.1.4). This result points out that the social factors accelerate the trends and magnitudes of people vulnerability to floods. The cause of this increase could be that people lack access to knowledge and information on disaster risk reduction and management measures. For example, the results of the analysis revealed the average social conditions generating vulnerability to be $55 \%$ in the category of "very important" (Table 3.1.1). The social factors identified were lack of preparedness and early warning systems, lack of knowledge and skills to cope up with urgent needs and lack of local support institutions.

The results further revealed that the social elements at risk were "slightly vulnerable" with an average of $39 \%$ (Table 3.1.2). The elements at risk that were found slightly vulnerable include the health posts and school infrastructures. This outcome was observed to be due to lack of community ownership of the social facilities. Most community members regard social facilities as government infrastructures hence they pay little attention in their management. It was observed that this is the case because of limited trainings that members of the community receive from different stakeholders to make them understand the importance of community ownership of social services. The limited trainings was observed to be due to lack of human resources responsible for disaster risk management in the district.

The results revealed that the associations between demographic characteristics and social factors were not significant (Table 3.1.3). This result is different from the study conducted by Maferetlhane (2012) who stated that demographic variables such as age, sex and marital status influence people's vulnerability in the Northwest Province in South Africa. However, this difference could be due to the nature of social factors that were used to associate the demographic variables. For example, Maferetlhane (2012) states that the social factors that increase people's vulnerability include limited access to health, education and housing while this study used the more technical social factors such as lack of preparedness and early warning systems, lack of knowledge and skills to cope up with urgent needs and lack of local support institutions.

3.2.1.3 Economic Factors: The economic factors showed a weak (but positive) correlation between economic factors and flood severity of the past floods $(r=0.262)$ and for the recent floods ( $r=0.477)$ (Table 3.1.4). This result points out that the economic factors determine the trends and magnitudes of people vulnerability to floods. However, on the economic conditions generating vulnerability the findings of the analysis revealed that the economic conditions generating vulnerability with an average of 55\% in the category of "very important" (Table 3.1.1), were poverty, lack of alternative likelihoods, and low income.

The analysis further revealed that the economic elements are vulnerable with a high average of $63 \%$ in the scale category of "vulnerable" (Table 3.1.2). Though the analysis of the average of economic elements was revealed to be vulnerable, some elements like maize and cassava, rice and livestock were on the category of severely vulnerable. Furthermore, the findings of the results indicate that trading was found slightly vulnerable on both scale category of severely vulnerable and slightly vulnerable while fishing was found to be vulnerable and not vulnerable on the scale of slightly vulnerable and severely vulnerable respectively.

Except occupation ( $p=0.0375$, Chi square $=30.436$ ), all the demographic characteristics were not associated with the economic factors (Table 3.1.3). It can be argued that the economic factors associated with occupation because most households were found to depend on farming as a source of occupation. Similarly, the survey established that women are the most economically vulnerable to floods due to their marital status. This is because widowed and divorced women fail to plant their crops at the right time, a condition that gives them limited access to economic resources.

3.2.1.4 Environmental Factors: The results showed a weak (but positive) correlation between environmental factors and flood severity of the past floods $(r=0.125)$ and a medium correlation of the recent floods $(r=0.578)$ (Table 3.1.4). This result points out that the environmental factors accelerate the trends and magnitudes of people vulnerability to floods. For example, the results of the household survey revealed that the environmental conditions generating vulnerability with average of $60 \%$ in the category of "very important" (Table 5 ), are residing in flood prone areas, pressure on land and lack of energy sources. The analysis of the vulnerability of the elements at risk revealed that environmental elements tend to be "slightly vulnerable" to floods. The elements found in this case category included forest and natural pasture, while rivers and soil and land. However, based on individual element, the results showed variation of vulnerability, for example river channels was on the category of vulnerable.

\section{Volume 9 Issue 4, April 2020 www.ijsr.net}




\section{International Journal of Science and Research (IJSR) \\ ISSN: 2319-7064}

ResearchGate Impact Factor (2018): 0.28 | SJIF (2019): 7.583

The results showed a significant association between sex, marital status, education and environmental factors. This suggests that the environmental factors influence the vulnerability of people to respond to floods based on sex, marital status and education. The relationship between sex and environmental factors showed that both men and women face numerous challenges during floods. For example, it was revealed that men find it difficult to graze their livestock because all the pasture gets submerged in water. Therefore, men are forced to travel long distances to search pasture for their livestock. Sometimes they are forced to identify other people in the hilly areas of Chipake, and Malili to keep their livestock until the flood subside. On the other hand, it was revealed that women find difficulties where to get firewood. The survey established that the majority use maize cobs during time of floods and animal dung after floods for cooking due to lack of firewood. It was further revealed that women walk long distances to fetch water because all the water sources especially shallow wells get contaminated with flooded water.

3.2.1.5 Cultural Factors: The results (Table 3.1.1) showed that cultural factors are not very important in generating vulnerability. The analysis revealed a less average percentage on the category of "very important" (33\%) than on the category of "important" $(37 \%)$ and less than the benchmark 50\% altogether (Table 5). The cultural factors found to generate vulnerability include absence of ownership, cultural conflicts, defiance to safety measures and traditional beliefs. The results revealed a strong correlation of the recent floods $(r=0.897)$ with the cultural factors. Furthermore, the results showed that the relationship of the cultural factors and past floods were significant (Table 3.1.4). This result showed that culture is the most important factor contributing to determining the trends and magnitudes of vulnerability to floods.

\subsubsection{Policy Implications in Vulnerability Trends and Magnitudes}

We argue that the availability (or unavailability) of disaster risk reduction policy interventions to address the generation of vulnerability has a bearing in the way people respond to hazards and disasters. Our observations and analysis revealed that most disaster risk reduction policy interventions address the root causes of vulnerability factors. These interventions do not properly address the three stages (root causes, dynamic pressures and unsafe conditions) that contribute to the generation of vulnerability because of a number of the following reasons:

(a) Firstly, lack of knowledge by stakeholders and people in disaster risk reduction. We observed that most those charged with responsibility do not have clear understanding of disaster risk reduction measures.

(b) Secondly, lack of financial resources hinder speedy implementation of disaster risk reduction interventions. This poses difficulties for the authorities in local councils to effectively assist people with strong DRR measures such as construction of dykes among others. Even timely response to emergency management of disaster becomes a huge challenge to officials to respond to disasters due to limited funds.

(c) Thirdly, lack of human capacity further aggravates the situation - thereby contributing to increase people's vulnerability. The Karonga district, like most districts in Malawi, has one disaster risk reduction officer responsible for disaster management. This is a challenge because in the event that the designated officer is out to attend other official duties, the work is delegated to people with little understanding of disaster risk measures.

(d) Fourthly, lack of community consultative efforts to fully strengthen emergency management of floods. This presents a challenge to local authority to identify and implement plans and mechanisms to respond effectively during emergencies including early warning systems.

(e) Fifthly, recovery schemes are not planned well to reduce future vulnerability because it was observed that people still construct their homes with same building materials and techniques that caused them to collapse.

(f) Sixthly, lack of government commitment to enforce policies with strict penalties coupled with insufficient resources to fully develop the infrastructure to meet the emergency management needs of the general public remains a major challenge to Malawi as a nation and is contributory to vulnerability.

(g) Lastly, we observed that people are unwilling to relocate for the following reasons:

- Weak enforcement of policies to curb settlements located in marginal and hazardous areas;

- High reliance on relief items to support flood victims by government and other stakeholders;

- Poor economic status and insufficient capacity by inhabitants to establish evacuation shelters and social services such as schools and health facilities in areas where they are relocated,

- Lack of capacity by local authorities and poorly defined policies for addressing issues of the evacuated land.

In view of all these reasons people are inclined to continue living in the same areas and thereby get impacted by flood disasters whenever they occur.

\section{Conclusion}

We conclude that the extent of vulnerability associated with floods in the Karonga study area is very high. We have demonstrated the different degrees or extent to which the five underlying factors i.e. physical- social- economicenvironmental and cultural factors influence the generation, trends and magnitudes of people's vulnerability to respond to flood disasters in Karonga District. The observations and statistical analysis revealed that most disaster risk reduction interventions need to address the root causes of vulnerability factors.

A variety of issues influences the vulnerability of men, women, children and the elderly in responding to flood disasters. Some of these issues include lack of disaster risk knowledge among communities. This includes individuals of Village Civil Protection Committees (VCPC) and Area Civil Protection Committees (ACPC) with low education levels but are tasked with disaster reduction responsibilities. The communities which lack risk disaster reduction strategies in all aspects of shelter safety and poor access to diversified livelihoods due to dependency on subsistence farming are also a contributory factor. Furthermore, a host of other issues play a role in influencing vulnerability. These issues

\section{Volume 9 Issue 4, April 2020}




\section{International Journal of Science and Research (IJSR) \\ ISSN: 2319-7064}

ResearchGate Impact Factor (2018): 0.28 | SJIF (2019): 7.583

include continued habitation of flood prone areas, cultural practices and land governance policies, weak enforcement of remedial legislation due to chieftaincy wrangles, weak government political will as well as inadequate human resources coupled with inadequate funds to support disaster risk reduction activities (e.g. construction of dykes and evacuation shelters). Finally, we recommend that stakeholders should be committed in designing and implementing effective disaster reduction projects in order to deal with the unveiled mix of factors contributing to communities' vulnerabilities.

\section{References}

[1] Anderson, M. \& Woodrow, P. (1989). Raising from the ashes: Development strategies at times of disaster. Colorado: Westview Press Boulder.

[2] Annan, K. (2003). Message for the International Day for Disaster Reduction. Retrieved from: http://www.unisdr.org/eng/public_aware/world _camp/2003/pacamp03-sg-eng.htm.

[3] Ariyabandu, M. M. \& Wickramasighe, W. M. (2005). Gender dimension in disaster management: A guide for South Asia. Sri Lanka, Practical Action Publishing Ltd.

[4] Aysan, Y. F. (1993). Keynote paper: Vulnerability assessment. In Merriman and Browitt, (Eds). Natural Disasters Protecting Vulnerable communities. London, United Kingdom, Ice publishing pp. 1-14.

[5] Banda, F. K. Z. (2015). The role of contextual factors in flood impact vulnerability in the context of climate change: Case study of Ndilande and South Lunzu, Blantyre City (Master's thesis), The University of Twenties, Enschede, Netherlands.

[6] Bath, J. R. et al. (2016). Vulnerability of coastal community from storm surge and flood disasters. Lynch: Jackson State University.

[7] Baumwoll, J., (2008). The value of indigenous knowledge for disaster risk reduction: A unique assessment tool for reducing community vulnerability to natural disasters (Master's thesis). Webster University, Vienna, Austria.

[8] Birkmann, J. \& Winner, B. (2006). Measuring the unmeasurable: The challenge of vulnerability. Bonn, Germany: UNU-IEH.

[9] Birkmann, J. (2006). Measuring vulnerability to promote disaster-resilient societies: Conceptual frameworks and definitions. Bonn, Germany: UNUIEH.

[10] Birkmann, J., Fernando, N. \& Hettige. (2006). Measuring vulnerability in Sri Lanka at the local level. In J. Birkmann (Ed). Measuring vulnerability to natural hazards: Towards disaster resilient societies (pp. 329-356). Tokyo: United Nations University.

[11] Blaikie P., et al. (2003). At risk: Natural hazards, people's vulnerability and disasters ( ${ }^{\text {nd }}$ Ed.). Latin America: La Red.

[12] Blaikie, P., et al. (1994). At risk: Natural hazards, people's vulnerability and disasters. London \& New York: Rutledge.

[13] Bohle, H. G. (2001). Vulnerability and criticality: Perspectives from social geography. Newsletter of the International Human Dimensions Programme on
Global Environmental Change: IHDP Update 2/2001, $1-7$.

[14] Brown, D. (2011). Making the linkages between climate change adaptation and spatial planning in Malawi. Environmental Science Policy, 14(8), 940949.

[15] Bryman, A. (2006). Integrating quantitative and qualitative research. How it done? Qualitative Research, 1(1), 8-22.

[16] Buckle, Marsh \& Smale (2001) Assessing Resilience \& Vulnerability: Principles, Strategies and Actions May 2001

[17] Buckle, P, Marsh G, and Smale, S., New approaches to assessing vulnerability and resilience, Australian Journal of Emergency Management Winter 2000 pp. 8 $-14$

[18] Canon, T. (2005). Vulnerability analysis and the explanation of natural disaster. London: University of Greenwich. pp. 15-21.

[19] Caracelli, V. J., et al. (1993). Data analysis strategies for mixed method evaluation designs. Education Evaluation and Policy Analysis, 15(2), 195-207.

[20] Cardona, O. D. (2004). The need for rethinking the concepts of vulnerability and risk from a holistic perspective: A necessary review and criticism for effective risk management. In G. Bankoff, G. Frerks \& D. Hilhorst (Eds.). Mapping vulnerability: Disasters, development and people (Chapter 3). London: Earth Scan.

[21] Chambers, R. (1989). Vulnerability, coping and policy. IDS Bulletin, 20(2), 1-7.

[22] KarongaDistrict Council (2016). KarongaDistrict Contingency Plan (2016). Karonga: Author.

[23] Ciurean, T. et al. (2013). Conceptual Frameworks of Vulnerability Assessments for Natural Disasters Reduction. Retrieved from http://dx.doi.org/10.5772/55538

[24] Concern Strategic Plan. (2005). Approaches to Disaster Risk Reduction. Bangladesh, Emergencies Unit Press: p 1-13.

[25] DoDMA. (2014). National Disaster Risk Management Communication Strategy (2014- 2018). Lilongwe, Malawi: Department of Disaster Management Affairs.

[26] DoPDMA. (2014). Department of Poverty and Disaster Management Affairs. Lilongwe, Malawi: Department of Disaster Management Affairs.

[27] Maferetlhane, O. I. (2012). The role of indigenous knowledge in disaster risk reduction: a critical analysis (Master's thesis), Potchefstroom: North-west University, South Africa.

[28] Salami, R.O., Von Meding, J.K. \& Giggins, H., (2017). Urban Settelements'vulnerability to floods in African cities: A conceptual Framework', Jamba: Journal of Disaster Risk Studies 9(1), a370. http://doi.org/10.4102/jamba.v9i1.370

[29] Trosper, R.L. (2002). Northwest Coast Indigenous Institutions that Supported Resilience and

[30] Tshilunga, S. E. (2014). A study of the 2011 floods on human security in Namibia (Master's thesis), The University of Namibia, Namibia.

[31] UNDP- Malawi (2016. Malawi: Ranking - HDI Human Development.

\section{Volume 9 Issue 4, April 2020 www.ijsr.net}




\section{International Journal of Science and Research (IJSR) \\ ISSN: 2319-7064}

ResearchGate Impact Factor (2018): 0.28 | SJIF (2019): 7.583

[32] UNDP-Malawi (T. Msowoya: personal email on February 3, 2009)

[33] Vincent, K. (2004). Creating an index of social vulnerability to climate change in Africa. Working Paper, No.56, Retrieved from http://www.tyndal.ac.uk/publications/workingpapers/wp56.pdf

[34] Wisner et al. (2004): The challenge of disasters and our approach. In: At risk: natural hazards, people's vulnerability, and disasters. Routledge, London

Volume 9 Issue 4, April 2020 www.ijsr.net 